\title{
Penetration of components of cervical fixation device into esophagus: An unexpected finding for the endoscopist
}

\author{
(D) Murat Ferhat Ferhatoglu, (1) Taner Kivilcim \\ Department of General Surgery, Okan University Faculty of Medicine, Istanbul, Turkey
}

Cite this article as: Ferhatoglu MF, Kivilcim T. Penetration of components of cervical fixation device into esophagus: an unexpected finding for the endoscopist. North Clin Istanb 2019;6(4):403.

A 73-year-old woman presented to the clinic with complaints of burning sensation in the chest, regurgitation of food and sensation of a lump in her throat which usually occurred after eating. She had a history of anterior cervical surgery for decompression, arthrodesis and fixation with a plate screwed at the C4-C6 vertebra level for a burst fracture of $\mathrm{C} 5$ vertebra over twenty years ago. Her blood pressure was $135 / 60 \mathrm{mmHg}$; heart rate was 68 /beat per minutes and body temperature was $37.1^{\circ} \mathrm{C}$. Lateral neck radiography and computed tomography showed a good fusion and normally positioned cervical fixation plate, and the contrast study showed an esophageal diverticulum and no evidence of fistula (Fig. 1). An esophagogastroscopy was conducted to evaluate the underlying reason for dysphagia, showed the penetration of a screw and the plate into the esophageal lumen. The esophagogastroscopy also showed a diverticular orifice close to screwing (Fig. 2). Proton pump inhibitor drug prescribed to her based on her symptoms and no evidence of leakage was present on the contrast study. The patient was invited one month later to our department, and all complaints of the patient disappeared. Plate displacement that caused penetration of screws or plates of fixation device after anterior cervical spine surgery is extraordinary, but a known complication. Trauma, recurrent cervical surgeries and chronic erosion of fixation device were accused of etiology.

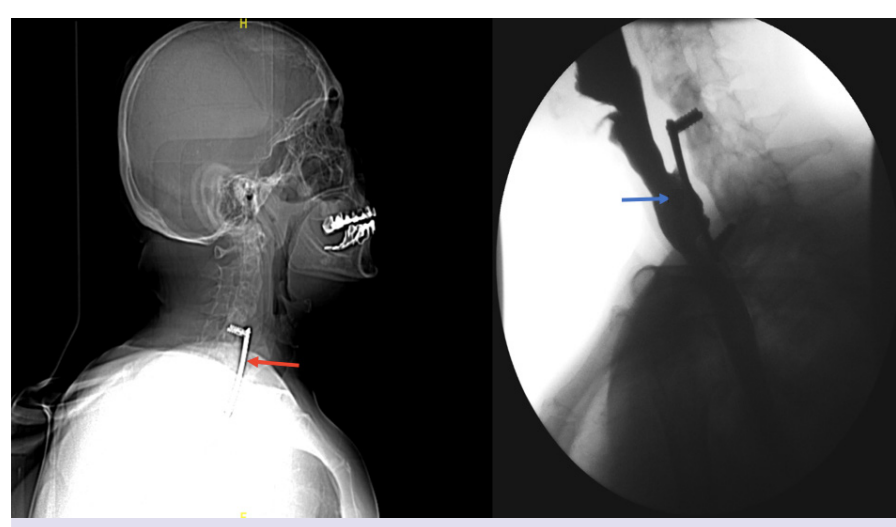

FIGURE 1. Lateral neck radiography normally showed normally positioned fixation plate (Red arrow), and no evidence of fistula was found on contrast study (Blue arrow).

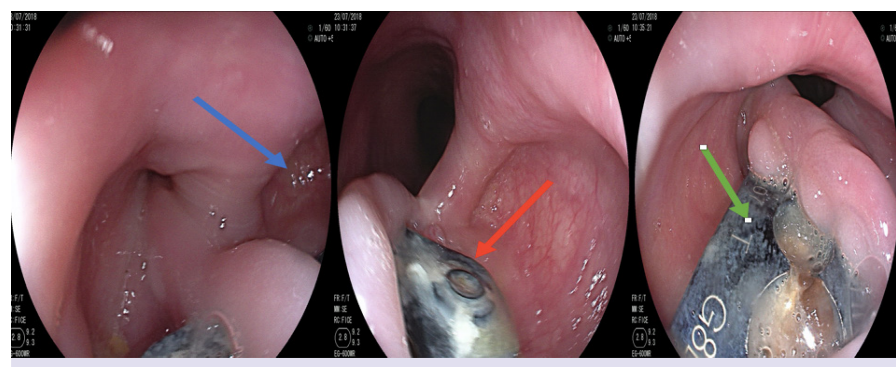

FIGURE2. Orifice of the esophageal diverticulum (Blue arrow), penetrated screw of fixation device (Red arrow), a penetrated plate of fixation device (Green arrow).

Received: October 18, 2018 Accepted: October 18, 2019 Online: October 24, 2019

Correspondence: Dr. Murat Ferhat FERHATOGLU. Okan Universitesi Tip Fakultesi, Genel Cerrahi Anabilim Dali, Istanbul, Turkey. 